\title{
Mechanism and reaction rate of the Karl-Fischer titration reaction. Part II. Rotating ring-disk electrode measurements
}

Citation for published version (APA):

Verhoef, J. C., \& Barendrecht, E. (1977). Mechanism and reaction rate of the Karl-Fischer titration reaction. Part II. Rotating ring-disk electrode measurements. Journal of Electroanalytical Chemistry and Interfacial Electrochemistry, 75(2), 705-717. https://doi.org/10.1016/S0368-1874(77)80056-7

DOI:

10.1016/S0368-1874(77)80056-7

Document status and date:

Published: 01/01/1977

\section{Document Version:}

Publisher's PDF, also known as Version of Record (includes final page, issue and volume numbers)

\section{Please check the document version of this publication:}

- A submitted manuscript is the version of the article upon submission and before peer-review. There can be important differences between the submitted version and the official published version of record. People interested in the research are advised to contact the author for the final version of the publication, or visit the $\mathrm{DOI}$ to the publisher's website.

- The final author version and the galley proof are versions of the publication after peer review.

- The final published version features the final layout of the paper including the volume, issue and page numbers.

Link to publication

\section{General rights}

Copyright and moral rights for the publications made accessible in the public portal are retained by the authors and/or other copyright owners and it is a condition of accessing publications that users recognise and abide by the legal requirements associated with these rights.

- Users may download and print one copy of any publication from the public portal for the purpose of private study or research.

- You may not further distribute the material or use it for any profit-making activity or commercial gain

- You may freely distribute the URL identifying the publication in the public portal.

If the publication is distributed under the terms of Article 25fa of the Dutch Copyright Act, indicated by the "Taverne" license above, please follow below link for the End User Agreement:

www.tue.nl/taverne

Take down policy

If you believe that this document breaches copyright please contact us at:

openaccess@tue.nl

providing details and we will investigate your claim. 
(C) Elsevier Sequoia S.A., Lausanne - Printed in The Netherlands

\section{MECHANISM AND REACTION RATE OF THE KARL-FISCHER TITRATION REACTION}

\section{PART II. ROTATING RING-DISK ELECTRODE MEASUREMENTS *}

\section{J.C. VERHOEF}

Laboratory of Analytical Chemistry; Free University, de Boelelcan 1085. Amsterdam (The Netherlands)

\section{E. BARENDRECHT}

Laboratory of Electrochemistry. University of Technology. P.O. Box 513, Eindhoven (The Netherlands)

(Received 19th Mav 1976)

\section{ABSTR ACT}

A platinum disk-platinum ring electrode was used to investigate the kinetics of the oxidation of the monomethyl sulfite ion (which is the oxidizable species in the Karl. Fischer reagent) by triiod de and iodine, generated with controlled current at the disk electrode. The experimental conditions were such, that the technique for measurement of horr. yeneous pseudo-first order reactions cuuld be used. The results are in reasonable agreeme $i \dot{w}$ with those of the potentiometric investigations as described in part $I$. The reaction rate constant of triiodide is approximately $600 \mathrm{I}^{2} \mathrm{~mol}^{-2} \mathrm{~s}^{-1}$; for iodine the rate constant is approximately $7 \times 10^{6}$.

\section{INTRODUCTION}

In part I [1] the oxidation of a methanolic sulfur dioxide solution by electrolytically generated triiodide and iodine has been studied by means of potentiometry. In the potentiometric experiments, the distance between the generating electrode and the indicator electrode is large $(\mathrm{ca} .3 \mathrm{~cm})$, compared to the distance between the disk electrode and the ring electroae (ca. 0.01 cm). Moreover, the potentiometric experiments are typically zero-current experiments; in the experiments with the ring-disk electrode, the current through the ring electrode is measured (at constant ring potential), while the current through the disk electrode is controlled. It was found that at pH values up to 5 , log reaction rate constant increases linearly with $\mathrm{pH}$, while at higher pH values the rate constant is invariant From this, we concluded that not sulfur dioxide itself, but a base, the monomethyl sulfite ion, is the

\footnotetext{
- In honour of Dr. G.C. Barker's 60th birthday.
} 
oxidizable species. It is formed from methanol and sulfur dioxide:

$\mathrm{SO}_{2}+\mathrm{CH}_{3} \mathrm{OH} \rightleftharpoons \mathrm{CH}_{3} \mathrm{SO}_{3}^{-}+\mathrm{H}^{+}$

$K_{n}=c_{\mathrm{CH}_{3} \mathrm{SO}_{3}} \cdot c_{\mathrm{II}^{+}} / c_{\mathrm{SO}_{2}}=10^{-5.10} \mathrm{~mol} \mathrm{l}^{-1}$ (at $25^{\circ} \mathrm{C}$ )

The oxidation of this base by iodine and triiodide in the presence of water appeared to be first order in each of the reactants: $\mathrm{I}_{2}$ and $\mathrm{I}_{3}^{-}, \mathrm{H}_{2} \mathrm{O}$ and $\mathrm{CH}_{3} \mathrm{SO}_{3}^{-}$. As long as the $\mathrm{pH}$ was fixed, addition of pyridine had no influence, so that pyridine does not play a role in the mechanism.

Because of the equilibrium between iodine and triiodide [2]:

$\mathrm{I}_{2}+\mathrm{I}^{-} \rightleftharpoons \mathrm{I}_{3}$

$K_{\mathrm{s}}=c_{\mathrm{I}}-1 c_{1_{2}} \cdot c_{\mathrm{I}}-=2.3 \times 10^{4} 1 \mathrm{~mol}^{-1}\left(\right.$ at $\left.25^{\circ} \mathrm{C}\right)$

there are always two oxidizing species, triiodide and iodine, with different reaction rate constants, $k_{13}$ and $k_{1_{2}}$, respectively. In part I it has been shown that the third order reaction rate, $k_{3}$, based on the simultaneous oxidation by triiodide and iodine, is given by

$\bar{k}_{3}=k_{I_{3}}+k_{I_{2}} / K_{s} c_{I^{-}}$

Therefore, a plot of $k_{3}$ vs. $1 / c_{\mathrm{I}}$ - gives a straight line with intercept $k_{\mathrm{I}_{3}}$ and slope $k_{\mathbf{I}_{2}} / K_{\mathrm{s}}$.

\section{THEORY OF MEASUREMENT}

In the measurements of homogeneous kinetics with the rotating ring-disk electrode, triiodide (and iodine) are generated at the disk electrode with controlled current from an iodide solution. The concentration of the iodide is so large, that at useful currents (say, less than $500 \mu \mathrm{A}$ ) and useful rotating speeds (say, more than 10 RPS) the limiting current is never reached. The potential of the ring electrode is set at such a value, that all of the triiodide that succeeds to reach the ring, immediately is reduced to iodide. From the theory of the ring-disk electrode [3], it follows, that if no triiodide reacts on its way from the disk to the ring, the collection efficiency, $N_{0}$, is a constant, independent of the rotation speed, the disk current and the iodide concentration. $N_{0}$ is defined as the absolute value of the ratio of the (cathodic) ring current to the (anodic) disk current. It can be measured and also calculated. $N_{0}$ is only a function of two parameters $\alpha$ and $\beta$ :

$$
\begin{aligned}
& \alpha=\left(r_{2} / r_{1}\right)^{3}-1 \\
& \beta=\left(r_{3} / r_{1}\right)^{3}-\left(r_{2} / r_{1}\right)^{3} \\
& N_{0}=1-F(\alpha / \beta)+\beta^{2 / 3}\{1-F(a)\}-(1+\alpha+\beta)^{2 / 3} \times \\
& \quad \times[1-F\{(\alpha / \beta)(1+\alpha+\beta)\}]
\end{aligned}
$$

where $r_{1}, r_{2}$ and $r_{3}$ are, the radius of the disk, the inner radius of the ring and 
the outer radius of the ring, respectively, and the function $F$ is given by

$F(x)=\frac{\sqrt{ } 3}{4 \pi} \ln \left(\frac{\left(1+x^{i / 3}\right)^{3}}{1+x}\right)+\frac{3}{2 \pi} \arctan \left(\frac{2 x^{1 / 3}-1}{\sqrt{3}}\right)+1 / 4$

If, on its way from the disk to the ring, some of the triiodide is reduced by the monomethyl sulfite, a smaller portion of it will reach the ring. One measures then a collection factor, $N_{k}$, that is not constant, but depends on the rotation speed of the electrode, the reaction rate constant and in some cases on the disk current.

In the literature two cases have been described:

(i) a (pseudo-) first order reaction, wheil the consumption of monomethyl sulfite and water is relatively small, so that the concentratior. of these substances can be considered to be constant [4], and

(ii) a (pseudo-) second order reaction, when the consumption of monomethyl sulfite is so fast, that near the disk electrode its concentration becomes small and it has therefore to be transported from the bulk of the solution by diffusive convection [5]:

It depends on the magnitude of $k_{2}$, the pseudo-second order rate constant, whether the reaction proceeds as a pseudo-first order or as a pseudo-second order reaction, With changing the water concentration we can vary the pseudosecond order rate constant, since

$k_{2}=h_{3} \cdot c_{\mathbf{H}_{2}} \mathrm{O}$

Therefore, at high water concentrations we have a pseudo-second order regime, where both the concentrations of triiodide and methyl sulfite vary (assuming that the water concentration remains constant). At low water concentrations, the reaction rate is slow enough to consider the methyl sulfite concentration. as practically constarit. In both cases we suppose that the methyl sulfite concentration is much lower than the water concentration. When the methyl sulfite concentration becomes very low, one would expect to find a second order regime. The value of $k_{1}$, however, decreases equally:

$k_{1}=k_{2} \mathrm{C}_{\mathrm{CH}_{3} \mathrm{SO}_{3}}$

so that the methyl sulfite concentration remains practically constant.

In a first order measuring technique the collection factor is a function of the ratio of the rate constant to the rotation speed, and independent of the disk current. Therefore, a plot of the ring current vs. the disk current gives a straight line through the origin with a slope $N_{\mathrm{k}}$, for which:

$0 \leqslant N_{k}=f\left(k_{1} / \omega\right) \leqslant N_{0}$

In a second order measuring technique the collection fact,or is zero at low disk currents and increases at higher disk currents. The asymptote of the plot of $i_{R}$ vs: $i_{p}$ has a slope $N_{0}$ and intersects the disk cuirent axis in a point where. 
$N_{0} i_{\mathrm{D}}=1.88 \times 10^{5} \times \beta^{2 / 3} r_{1}^{2} n D^{2 / 3} \nu^{-1 / 6} \omega^{1 / 2} c_{\mathrm{CH}_{3} \mathrm{SO}_{3}}^{\circ}$

(All symbols have their usual significance; $\omega$ is expressed in rad $\mathrm{s}^{-1}$ ). In most of the experiments the water concentration was small enough (usually less than $0.1 M$ ) to establish a pseudo-first order regime. Then the ratio of $N_{k}$ to $N_{0}$ is a function of $\lambda$, where

$\lambda=2.60(\nu / L)^{3 / 3}\left(k_{1} / \omega\right)$.

No analytical function, describing the dependence of the ratio of $N_{k}$ to $N_{0}$ on $\lambda$, has proved to be possible. However, approximate analytical expressions are found that satisfy well over certair. ranges of values of $\lambda$. For $\lambda<1.7$, use is made of an approximate collection efficiency:

$N_{0}^{\prime}=\left(\beta^{\prime}\right)^{2 / 3}\left(1-\frac{\sqrt{3}}{\pi}\left(\alpha^{\prime}\right)^{1 / 3}\right)-\frac{2}{3}\left(\alpha^{\prime}+\beta^{\prime}\right)\left\{1-F\left(\alpha^{\prime} / \beta^{\prime}\right)\right\}$

with $\alpha^{\prime}=3 \ln \left(r_{2} / r_{1}\right)$ and $\beta^{\prime}=3 \ln \left(r_{3} / r_{2}\right)$

while $F(x)$ is given by (7).

From this, an approximate kinetic collection factor is calculated:

$N_{\mathrm{k}}^{\prime}=N_{\mathrm{o}}^{\prime}-\left(\beta^{\prime}\right)^{2 / 3}\left(1-\frac{\operatorname{tani} \sqrt{ } / \lambda}{\sqrt{\lambda}}\right)+0.160\left(\beta^{\circ}\right)^{4 / 3} \sqrt{ } \lambda \tanh \sqrt{ } \lambda-0.879 T_{2} \lambda$

The small term $T_{2}$ only depends on the electrode dimensions, and is set out in the literature $[6]$. When $\alpha^{\prime}=\beta^{\prime}, T_{2}$ equals $0.115\left(\alpha^{\prime}\right)^{5 / 3}$. The approximation is corrected for by putting

$N_{\mathrm{k}}=\left\{1+\left(1-\tanh ^{2} \sqrt{ } \lambda\right)\left(N_{\mathrm{o}} i N_{\mathrm{o}}^{\prime}-1\right)\right\} N_{\mathrm{k}}^{\prime}$

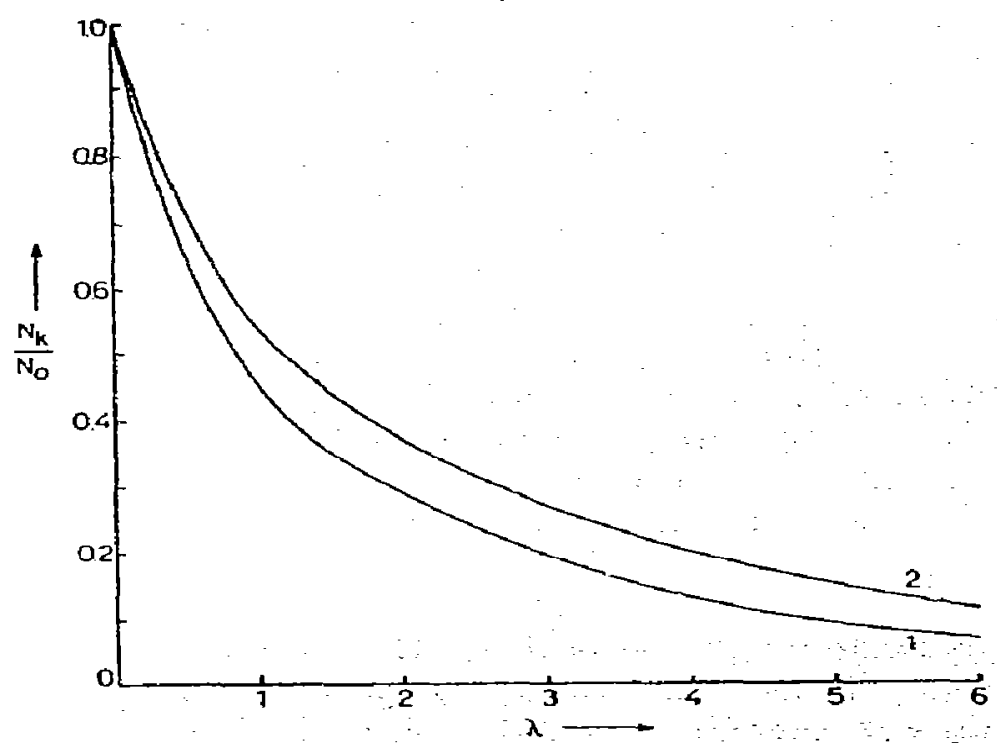

Fig. 1. Calibration curves for the twc electrodes (No. 1 and 2 , wee Table 1 ): 
For $\lambda<0.15$, it is hetter to calculate $\boldsymbol{N}_{\mathrm{k}}^{\prime}$ in a somewhat different way:

$$
\begin{aligned}
N_{\mathrm{k}}^{\prime} & =N_{\mathrm{o}}^{\prime}+\left(\beta^{\prime}\right)^{2 / 3}\left(0.3 / 2 \lambda-0.146 \lambda^{2}\right)+\left(\beta^{\prime}\right)^{4 / 3}\left(0.160 \lambda-0.059 \lambda^{2}\right) \\
& -0.879 T_{2} \lambda
\end{aligned}
$$

However, when calculating $\lambda$ from a measured $N_{\mathrm{b}} / N_{0}$ value, the increase in accuracy is small if (17) is used instead of (15).

For $\lambda \rightarrow 1.7, N_{\mathrm{k}} / N_{0}$ is calculated with

$N_{k} / N_{0}=\exp [\neg \alpha \kappa+b-\ln \{(\kappa+c+1) /(\kappa+c)\}]$

where $k=0.776 \lambda^{1 / 2}$ and the constants $\alpha, b$ and $c$, only depending on the electrode dimensions, are tanulated in the literature [f].

A plot of $N_{k} / N_{0}$ vs. $\lambda$ for two different electrodes is stown in Fig. 1 . Although it looks cumbersome to calculate the points of the plot, it is easily done by using a programinable desk calculatior or a computer. For that matter, it only has to be done once for a single electrode. Once a plut has been made, it is easy to find $k_{1}$ from a measured $N_{k} / N_{0}$ value.

\section{EXPERIMENTAL}

Reagents and procedure

The reagents used in this investigation are essentially the same as those used in part I. The procedure also is the same for the determination of the $\mathrm{pH}$ and the concentrations of water and sulfur dioxide. The experiments were carried out in a dry $\mathbf{N}_{2}$ atmosphere, and the temperature was maintained at $25.0 \pm 0.3^{\circ} \mathrm{C}$ (unless otherwise stated).

The electrodes: were cleaned before the experiments by polishing with alumina (0.1 $\mathrm{\mu m}$, Fischer Scientific Co.), then rinsing with, successively, water, ethanol and methanol and finally by enodic polishing (in a separate $\mathrm{LiNO}_{3}$ solution in methanol).

\section{Apparatus}

Two exchangeable ring-disk electrodes have been used, both developed and manufactured in our laboratory. The ring and the disk were made of platinum and the electrode bojy was made of Kel-F. The electrodes were mounted in a fitting that was ćriven by a servomotor with tachozenerator (type Motomatic, Electro-craft Corporation, Hopkins, Minn., U.S.A.). The rotating fitting was supported by a stationary collar in such $\mathrm{q}$ way that the system was air-sealed at al rotation speeds (0-85 rps). Precise measlirements of the rotation speed were performed by means of a disk, attached to the motor, with ten holes at the edge.

The disk interrupted the light beam between a light emitting diade and a phototransistor. The pulse frequency was measured with a Hewlett-Packand, 
model 5304 A, counter. The electrodes were controlled by a Tacussel, model Bi-pad, bipotentiostat/galvanostat, with independent control of the disk and ring potentials (in the potentiostat mode), or the disk current and the ring potential (in the galvanostat mode). The current was programmed with a Tacussel signal generator (model GSTP). Recordings were made on a Hewlett-

Packard model 7046 A XY recorder.

\section{RESULTS AND DISCUSSION}

The characteristics of the two electrodes are tabulated in Table 1: Although, according to the theory of the ring-disk electrode, the collection efficiency should be constant at different rotation speeds, we found a small rariation of $N_{0}$ (only a few percent). Moreover, the measured value of $N_{0}$ differs somewhat from the calculated value. Therefore, we did not plot $N_{k}$ vs. $\lambda$ for the calibration curve, but instead, we plotted $N_{k} / N_{0}$ vs. $\lambda$. Each measurement was usually performed at four or five rotation speeds; by dividing a $\boldsymbol{N}_{\mathrm{k}}$ value at a given rotation speed by the $N_{0}$ value at the same rotation speed, we corrected for the variation of $N_{0}$ and for the difference between calculated and measured $N_{0}$ values.

Generally, the water and/or sulfur dioxide concentration was chosen such, that the $N_{k} / N_{0}$ values were between 0.7 and 0.2 . In this range the best accuracy was obtained (see Fig. 1). In order to calculate a $k_{1}$ value from an experimental $\lambda$ value, one rieeds to know the viscosity coefficient of the solution, $\nu$, and the diffusion coefficient of the triodide ion, $D$. Neither of them needs to be known very accurately, since only $(\nu / D)^{1 / 3}$ has to be known. We used a Ubbelohde viscometer to measure the viscosity of the solutions $(\nu=9.41$ $\times 10^{-7} \mathrm{~m}^{2} \mathrm{~s}^{-1}$ for a solution with ionic strength 0.5 at $25^{\circ} \mathrm{C}$ ). The diffusion coefficient of the trīodide ion is $1.09 \times 10^{-9} \mathrm{~m}^{2} \mathrm{~s}^{-1}[2]$, so that $(v / D)^{1 / 3}$

\section{TABLE 1}

Characteristics of the electrodes No. 1 and 2

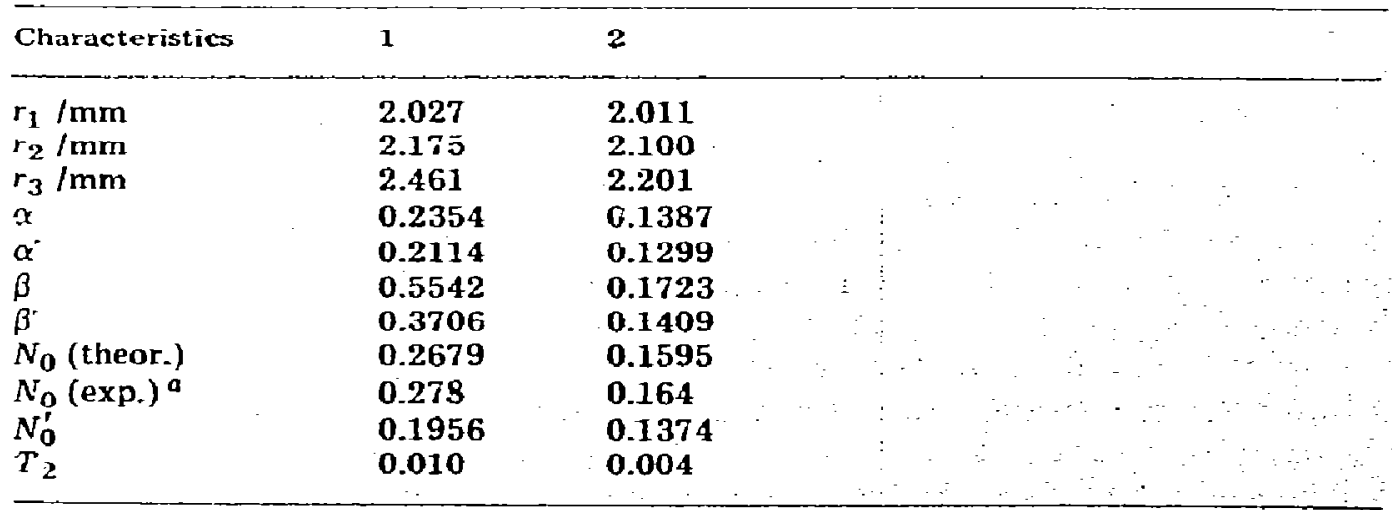

a Measured in a $0.5 \mathrm{M} \mathrm{NaI}$ solution in methanol at $25 \mathrm{rps}$. 


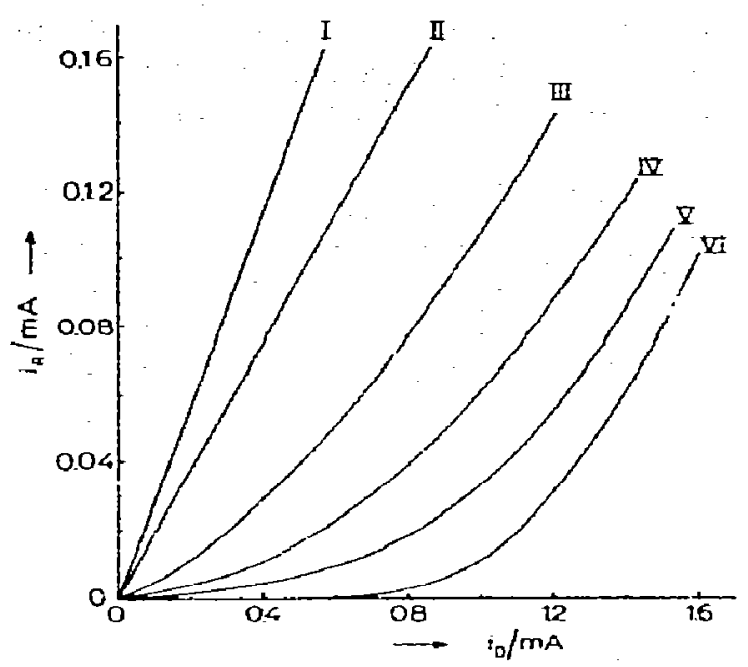

Fig. 2. Typical $i_{\mathrm{R}}$ vs. $i_{\mathrm{D}}$ curves for different mole fractions of water. $E_{\mathrm{R}}-0.2 \mathrm{~V}$ vs. SCE: $\omega=20 \mathrm{rps} ; c_{1}-=0.5 \mathrm{H} ; c_{\mathrm{SO}_{2}}$ (total) $=7.4 \mathrm{mM} ; \mathrm{pH}=2.0 ; x_{\mathrm{H}_{2}} \mathrm{O}=0$ (I), 0.15 (II), 0.24 (III), 0.29 (IV), 0.34 (V), 0.46 (VI).

equals 9.52. This val de vias fairly independent of the temperature and the composition of the solution.

The consumption of the triiodide formed at the disk electrode occurs by a pseudo-first order reaction unless the water concentration becomes high (Fig-2). At low water concentrations, the $i_{k}$ vs, $i_{p}$ curves are straight lines through the origin, but at high water concentration the reaction is so fast, that the consumption of sulfur aioxide (methyl sulfite) cannot be neglected and the reaction is pseudo-second order, as is indicated by the typical J-shaped $i_{R}$ vs. $i_{D}$ curves. In the intermediate cases, the first part of the $\dot{i}_{R}$ vs. $i_{D}$ curves is linear and there a first, order calculation can be applied. Then, the accuracy can be improved by using the lower disk current settings of the galvanostat. When iodide and sulfur dioxide are both present, the solution is yellow. This is caused by the formation of a relatively weak compiex, $\mathrm{SO}_{2} \mathrm{I}$, as has been found in other solvents, e.g. water and acetonitrile [7].

The complex has a maximum absorbance at $354 \mathrm{~nm}$, while at this wavelength neither iodide nor aulfur dioxide show any appreciable absorbance. The stability constant, $\tilde{K}_{c}$, and the absorptivity, $\epsilon$, of the sulfur dioxide-iodide complex can be found from a plot of $1 / A$ (absorhance) vs. $1 / c_{\mathrm{SO}_{2}}$, since at relatively lange $\mathrm{CSO}_{2}[8]$ :

$\left(c_{1}-+c_{\mathrm{SO}_{2} \mathrm{I}}-\right) / A=1 / 6 K_{\mathrm{c}} c_{\mathrm{SO}_{2}}+1 / \epsilon$

We found: $\epsilon=(1,29 \pm 0.13) \times 10^{3} 1 \mathrm{~mol}^{-1} \mathrm{~cm}^{-1}$

$$
K_{\mathrm{c}}=c_{\mathrm{SO}_{2} \mathrm{I}}-1 c_{\mathrm{SO}_{2}} c_{\mathrm{I}}=1.24 \pm 0.131 \mathrm{~mol}^{-1}
$$

Because of this yellow complex, it is not possible to have an optical end-point 
indication in an ordinary Karl-Fischer titration, for even at $\mathrm{pH} \approx \mathbf{7}$, the soluiion contains usually enough of the complex to color it yellow (although at this pH only a very small part of the total amount of sulfurous compounds is present as the iodide complex).

For the calculation of the reaction rate, one needs to know both the part of the total (analytical) sulfur dioxide concentration that is present as the monomethyl sulfite ion, and the part of the total (analytical) iodide concentration that is present as iodide, because we can only measure the total iodide and sulfur dioxide concentrations. Let the total sulfur dioxide and iodide concentrations be $a$ and $b$, respectively:

$a=c_{\mathrm{SO}_{2}}+c_{\mathrm{SO}_{2} \mathrm{l}}-+c_{\mathrm{CH}_{3} \mathrm{SO}_{3}}$

$b=c_{1}-+c_{\mathrm{SO}_{2} \mathrm{I}^{-}}+c_{\mathrm{I}_{3}}$

Since very little iodine is present we may neglect the equilibrium between iodine and iodide (2), so that the term $c_{1}-$ may be omitted from (20). Then, one can derive

$c_{\mathrm{I}}-=\left\{B+\left[B^{2}+4 K_{\mathrm{c}} \mathrm{b}\left(K_{\mathrm{a}} / c_{\mathrm{H}}+1\right)\right]^{1 / 2}\right\} / 2 K_{\mathrm{c}}$

where

$B=K_{\mathrm{c}}(b-a)-\left(K_{\mathrm{a}} / c_{\mathrm{H}^{+}}+1\right)$

and $c_{\mathrm{H}^{+}}$is put equal to $10^{-\mathrm{pH}}$, while

$\operatorname{liCH}_{3} \mathrm{SO}_{3}=a \cdot K_{\mathrm{a}} /\left\{K_{\mathrm{a}}+c_{\mathrm{H}^{+}}\left(1+K_{\mathrm{c}} \mathrm{C}_{\mathrm{I}^{-}}\right)\right\}$

Except for the term $K_{c} c_{I}-$, (22) is equivalent to eqn. (20) of part I. Often, the corrections for the formation of the complex are small. When the pH is one or two units larger than $\mathrm{p} K_{\mathrm{a}}$, almost all sulfur dioxide is present as monomethyl sulfite, so that the formation of the complex $\mathrm{SO}_{2} \mathrm{I}^{-}$can be rieglected. At $p H<p K_{2}$, however, most of the sulfur dioxide is present as such, and, especially at high iodide concentrations, the formation of the complex is important. If the iodide concentration decreases considerably as a result of the formation of the complex, the reaction rate increases (c.f. part I and below), so that the effects cancel out to some extent. Anyhow, where needed, a correction for the formation of the complex has been made.

We measured the reaction order with respect to sulfur dioxide and water at $\mathrm{pH}=\mathbf{5 . 0}$ and at $\mathrm{pH}=6.6$ (Fig. 3 ). Either the water concentratior or the sulfur dioxide concentration was kept constant (within 10\%), while varying the $\mathrm{c}_{\mathrm{SO}_{2}}-c_{\mathrm{H}_{2} \mathrm{O}}$ product. The straight lines indicate that the reaction is first order in water as well as in sulfur dioxide. At increasing water concentrations the stoichiometry of the $\mathrm{Karl}$-Fischer reagent increases from one mole $\mathrm{H}_{2} \mathrm{O}$ per mole $\mathrm{I}_{2}$ (or $\mathrm{I}_{3}^{-}$) to two mole; $\mathrm{H}_{2} \mathrm{O}$ per mole $\mathrm{I}_{2}$ [9]. In that case, the relation between the reaction rate and the water concentration could be nonlinear. In Fig. 4, the logarithm of the pseudo-second order reaction rate constant (i.e. the measured pseudo-first oruer rate constant divided by the sulfur 


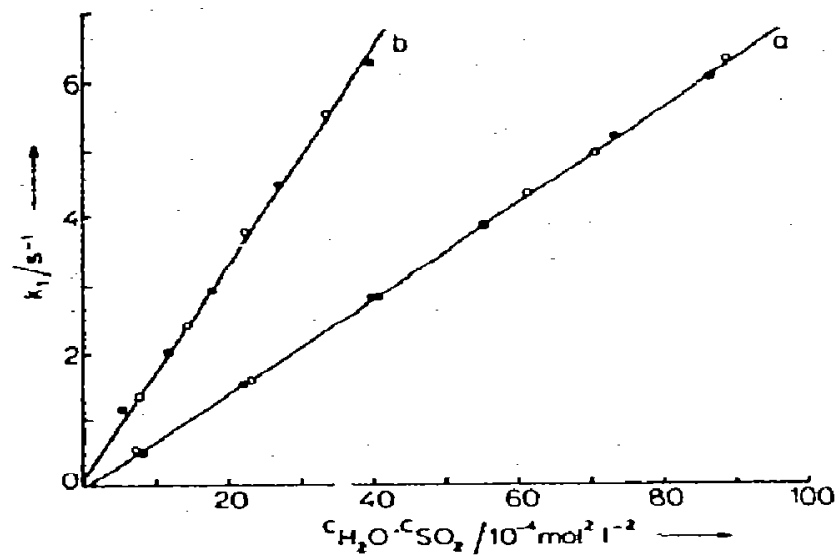

Fig. 3. First order reaction rate constant as a function of change in concentration. (a) pH $=5.0$. (๑) $c_{\mathrm{H}_{2} \mathrm{O}}=129 \mathrm{mM},(\mathrm{O}) c_{\mathrm{SO}_{2}}=10.9 \mathrm{mM} ;$ (b) $\mathrm{pH}=6.6,(\bullet) c_{\mathrm{H}_{2} \mathrm{O}}=75 \mathrm{mM},(0)$ $c_{\mathrm{SO}_{2}}=8.6 \mathrm{mM}$.

dioxide concentration) is plotted vs. the logarithm of the water concentration. Up to ca. $1 M \mathrm{H}_{2} \mathrm{O}$ the slope of the curve is 1 , while at higher concentrations it increases to a value of about 2 . Probably, bisulfite is formed:

$\mathrm{SO}_{2}+\mathrm{H}_{2} \mathrm{O}=\mathrm{HSO}_{3}^{-}+\mathrm{H}^{+}$

whereafter this bisulfite reacts with iodine or triiodide and a second water molecule: hence a stoichiometric factor that increases from 1 (only methyl sulfite formed) to 2 (mainly bisulfite formed). In order to have a known and constant stoichiometric factor, it is therefore necessary to keep the water concentration always as low as possible, in any case lower than $1 M$. Although

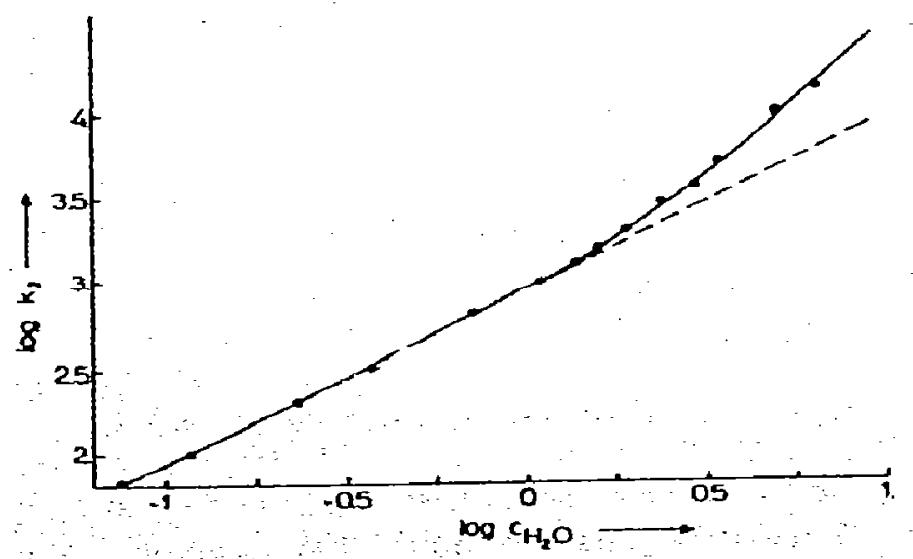

Fig-4-Variation of $h_{2}$ with large $c_{\mathrm{ff}_{2}} \mathrm{O}$ 


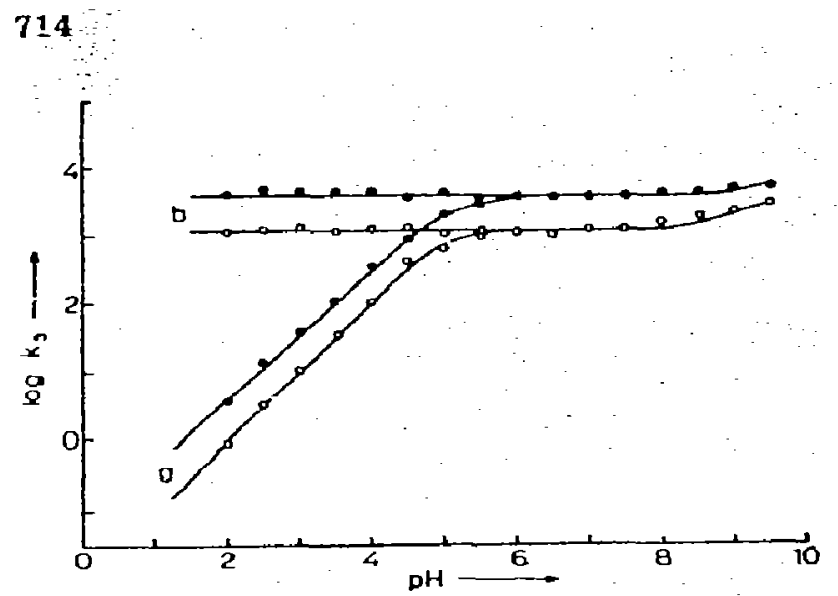

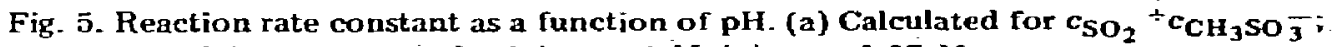
(b) calculated for $c_{\mathrm{CH}_{3}} \mathrm{So}_{3}^{-}$only. (o) $c_{\Gamma^{-}}=1 \mathrm{M}$, (a) $c_{1^{-}}=0.07 \mathrm{M}$.

it seems easy to fulfill this condition one must bear in mind that, owing to the small molar weight of water, it amounts to only about $2 \%$ of water in methanol:

The reaction rate of the Karl-Fischer reaction has been measured as a function of the pH for a small and for a large iodide concentration (Fig. 5). When we calculate the reaction rate constant for the total sulfur dioxide concentration (i.e. for $\mathrm{c}_{\mathrm{SO}_{2}}+c_{\mathrm{CH}_{3} \mathrm{SO}_{3}}$ ), we find a $\mathrm{pH}$-dependent rate constant. This indicates that not sulfur dioxide, but the monomethyl sulfite ion is the oxidizable species. Calculations for the consumption of only this species result in $p H$-independent rate constants, in complete agreement with the results of the potentiometric experiments.

At various $\mathrm{pH}$ values we measured the dependence of the reaction rate on the iodide concentration (Fig. 6). The plots of $k_{3}$ vs. 1/c - are straight lines, in accordance with (3). At $\mathrm{pH}=6.5$, the values of the rate constant for the total sulfur dioxide practically coincide with those for the monomethyl sulfite alone. From the intercept at this $\mathrm{pH}$ we find

$k_{\mathrm{I}}-=614 \pm 80 \mathrm{I}^{2} \mathrm{~mol}^{-2} \mathrm{~s}^{-1}$

and from the slope:

$k_{\mathrm{I}_{2}} / K_{\mathrm{S}}=316 \pm 51 \mathrm{~mol}^{-1} \mathrm{~s}^{-1}$

With $K_{S}=2.3 \times 10^{1} 1 \mathrm{~mol}^{-1}(2)$, we calculate:

$k_{\mathrm{I}_{2}}=(7.27 \pm 0.12) \times 10^{6} \mathrm{1}^{2} \mathrm{~mol}^{-2} \mathrm{~s}^{-1}$

These results are in reasonable agreement with the values found in frart $I$ : $k_{\mathrm{I}_{3}}=346 \pm 93$ and $k_{\mathrm{I}_{2}}=(8.83 \pm 0.32) \times 10^{6}$.

The temperature dependence of the reaction rate is shown in $\mathrm{Fig} .7: \mathrm{At}$ increasing temperature both the intercepts and the slopes of the lines increase. A plot of the logarithm of the intercepts and the slopes is shown in 


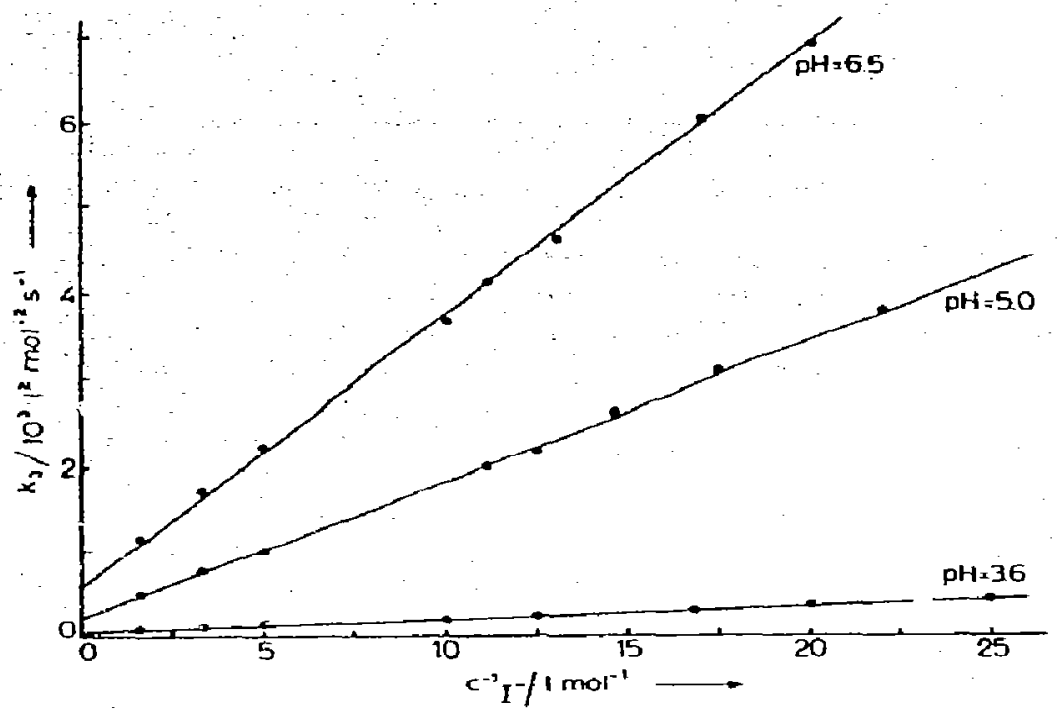

Fig. 6. Reaction rate constant as a function of the iodide concentration at different $\mathrm{pH}$ values.

Fig. 8 (a and $b$, respectively). The temperature dependence of the slope of the lines of Fig. 7 is almost the same as the temperature dependence of the stability constant of triiodide [2], so that the reaction rate with iodine is almost temperature independent (Fig. 8, c).

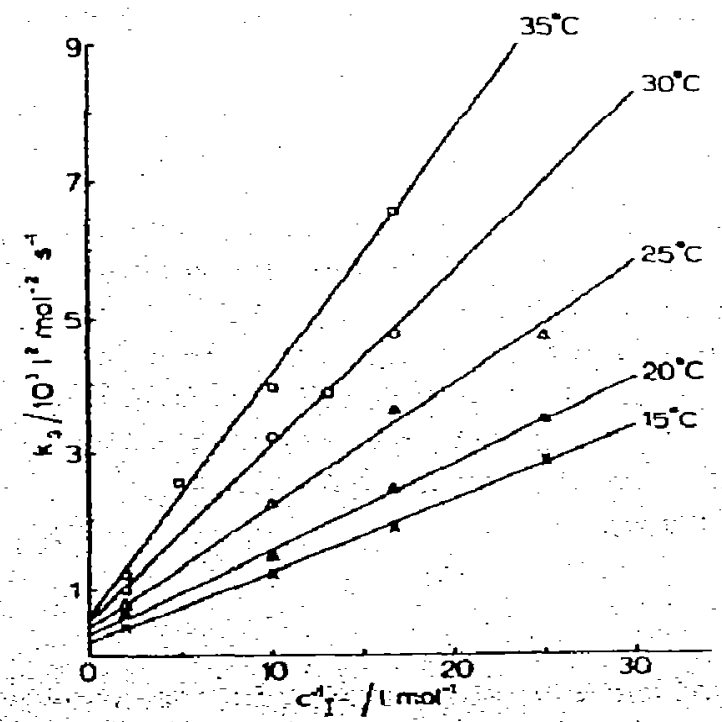

Fig. $T$ - Reaction rate constant as a function of the iodide concentration at different tem peratures $(\mathrm{pH}=7.3)$ 


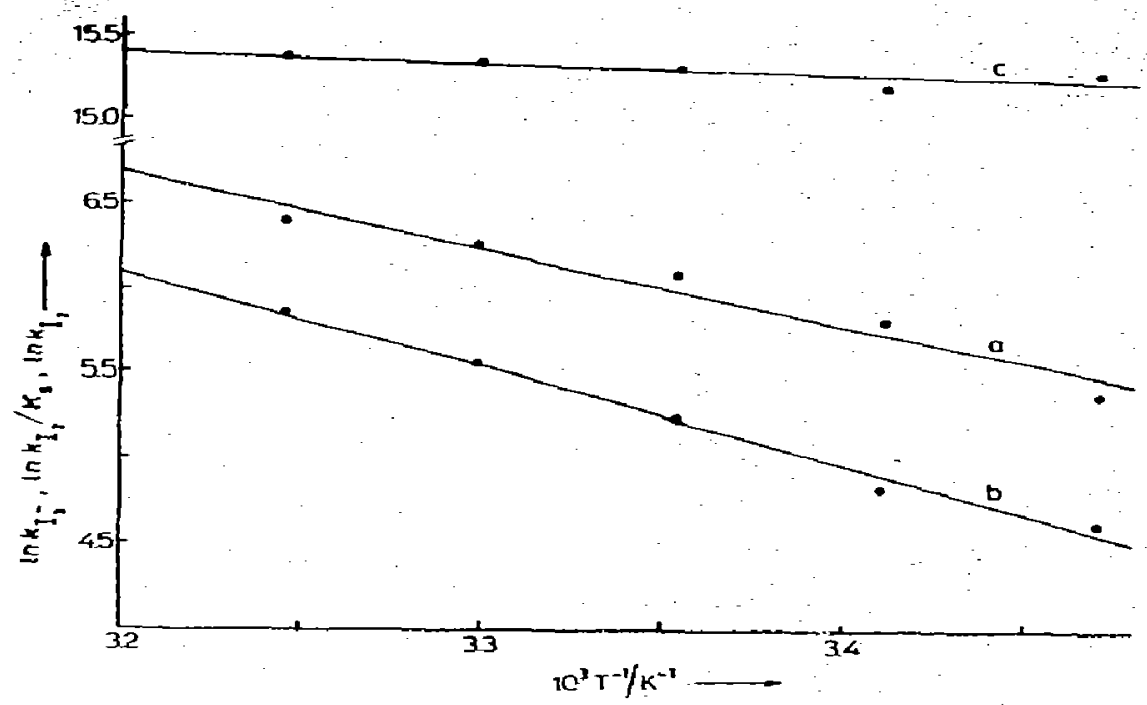

Fig. 8. Temperature dependence of (a) $k_{I_{3}}^{-}$, (b) $k_{I_{2}} / K_{3}$, (c) $k_{I_{2}}$.

From the intercepts of Fig. 8 we can calculate the entropies of activation of the Karl-Fischer reaction. We find for triicdide and iodine the values $-\mathbf{8 0}$ $\pm 20 \mathrm{JK}^{-1} \mathrm{~mol}^{-1}$ and $-100 \pm 15 \mathrm{JK}^{-1} \mathrm{~mol}^{-1}$, respectively. The enthalpies of activation, found from the slopes of Fig. 8 , are for triodide and iodine 34 $\pm 5 \mathrm{~kJ} \mathrm{~mol}-1$ and $2.2 \pm 1.7 \mathrm{~kJ} \mathrm{~mol}^{-1}$, respectively. The activation entropies are comparable within experimental error, so that probably in the reaction with triiodide and with iodine the same infermediate is formed. The low: activation enthalpy for the reaction with iodine is consistent with the large reaction rate found.

\section{CONCLUSION}

The rotating ring-disk electrode appears to be a convenient tool for measuring the rate of homogeneous reactions. Two very different electrochemical measuring techniques, potentiometry and ring-disk galvanometry, give comparable results. In a Karl-Fischer reagent a number of equilibria exists: the formation of the sulfur dioxide - iodide complex, the formation of triiodide and the formation of monomethyl sulfite. Along with these equilibria, the Karl-Fischer reaction proper is the oxidation of monomethyl suifite by iodine and triiodide in the presence of water.

\section{ACKNOWLEDGMENTS}

The instrument-makers department of the laboratory is gratefulty acknowl edged for manufacturing the electrodes and driving system. Thanks are also due to Mr. P. Pel for carrying out many of the experiments. 


\section{REFERENCES}

1 J.C. Verhoef and E. Barendrecht, J: Electrcanal. Chem., 71 (1976; 2gu.

2 J.C. Verhoef, W.H. Voogt and E. Barendreeht; to be published.

3 W.J. Albery and S. Bruckenstein. Trans. Faraday Soc., 62 (19G6) 1920.

4.J. Albery and S Bruckenstein, Trans. Faraday Soc., 62 (1966) 1946; W.J. Albery, ibid., 63 (1967) 1771: W.J. Albery, M.L. Hitchman and J. Ulstrup, ibid., 64 (1968) 2831 ; W.J. Albery, J.S. Drury and M.L. Hitchman, ibid., 67 (1971) 2162.

5. W.J. Albery, S. Bruckenstein and D.C. Johnson. Trans. Faraday Soc., 62 (1966) 1938; W.J. Albery and S. Bruckenstein, ibid.; 62 (1966) 2584; W.J. Albery, M.L. Hitchman and J. Ulstrup, ibid., 65 (1969) 1101.

6 W.J. Albery and M.L. Hitchman, Ring-Dise Electrodes, Oxford University Press. London, 1971 .

I A. Salama, S.B. Salama, M. Sobeir and Saad Warif, J: Chem. Soc. (A), (1971) 1112.

8 H.A. Benesi and J. Hildebrand, J. Amer. Chem. Sac., 71 (1949) 2703.

9 E. Eberius, Wasserbestimmung mit Kail-Fischer Lösung, Verlag Chemie, Weinheim, $2 a$ Aufl., 1958, pp. 35-49. 